\title{
Classification of Fish-Pathogenic Vibrios Based on Comparative 16S rRNA Analysis
}

\author{
RAGNHILD WIIK, ${ }^{1 *}$ ERKO STACKEBRANDT, ${ }^{2}$ OLAV VALLE, ${ }^{1}$ FRIDA LISE DAAE, ${ }^{1}$ \\ ODD MAGNE RØDSETH, ${ }^{3}$ AND KARI ANDERSEN ${ }^{3}$
Department of Microbiology and Plant Physiology, University of Bergen, N-5007 Bergen, ${ }^{1}$ and Institute of Marine Research, Department of Aquaculture, N-5024 Bergen, ${ }^{3}$ Norway, and Deutsche Sammlung von Mikroorganismen und Zellkulturen GmbH, 38124 Braunschweig, Germany ${ }^{2}$

\begin{abstract}
No systematic classification of fish-pathogenic vibrios has been accomplished previously despite the use of serological, physiological, and genetical classification systems. In this study, a comparative 16S rRNA analysis of 34 strains (representing seven species) of fish-pathogenic vibrios was performed. The 16S rRNA sequences were obtained by using reverse transcriptase. Nearly complete sequences were obtained for nine strains. On the basis of the results of this analysis, the remaining strains were investigated by analyzing selected stretches containing a total of 560 nucleotides. With the exception of a few strains, including ATCC 43313 (serovar 09), our comparative 16S rRNA analysis confirmed that strains preliminarily identified as Vibrio anguillarum were phylogenetically closely related. Strains of $V$. anguillarum could be divided into groups, with the main group containing serotype $\mathrm{O1}$ and $\mathrm{O2}$ strains isolated from Atlantic salmon, rainbow trout, turbot, cod, and saithe. The other distinctive group was represented by type strain NCMB 6. This strain was nearly indistinguishable from the type strains of Vibrio ordalii and Vibrio damsela on the basis of the 16S rRNA stretches compared. The results of a comparative 16S rRNA analysis justified the status of Vibrio salmonicida as a distinct species. Originally, this species was characterized biochemically as a very homogeneous species. However, two strains, which were isolated from diseased halibut and from the intestines of healthy cod, could not be distinguished from $V$. salmonicida strains phylogenetically, although they differed from the original species description in several phenotypic traits. Our results indicate that $V$. salmonicida and Vibrio fischeri form a cluster that is clearly separated from the cluster that includes $V$. anguillarum.
\end{abstract}

Vibriosis is the name given to a group of related systemic infections in fish that are caused by marine vibrios $(7,12)$. Variants of vibriosis occur worldwide and affect a great variety of fish species $(7,13,15,40,41,47,48,51,53)$, as well as crustaceans and molluscs $(4,5,20)$. Although vibriosis has been reported in complete freshwater aquaculture systems (17), this group of diseases is primarily a marine problem.

Historically, the fish-pathogenic vibrios have been assigned to the species Vibrio anguillarum $(1,2)$. This classification, however, has turned out to be an oversimplification $(27,41$, 48). Efforts have been made to bring order to the heterogeneous group of fish-pathogenic vibrios by establishing serological $(43,48)$ and physiological $(18,34)$ classification systems and by describing new Vibrio species (such as Vibrio salmonicida [13], Vibrio damsela [26], and Vibrio ordalii [41]) on the basis of both phenotypic and genotypic characteristics. Despite these efforts, a satisfactory systematic classification of the fishpathogenic vibrios has not been accomplished previously. The unresolved taxonomic affiliation of the fish-pathogenic vibrios is a problem for epidemiological studies and vaccination programs.

The goal of this study was to investigate whether fish-pathogenic vibrios could be unambiguously classified on the basis of the results of an analysis of their 16S rRNA sequences. In recent years, comparative 16S rRNA sequence analysis has become a very valuable tool for both delineation of evolutionary relationships $(16,54)$ and taxon identification $(45,55)$.

* Corresponding author. Present address: Rogaland Research, P.O Box 2503 Ullandhaug, N-4004 Stavanger, Norway.

\section{MATERIALS AND METHODS}

Bacterial strains. The strains which we examined, as well as their serotypes, origins, and nucleotide sequence accession numbers, are listed in Table 1 . The serotypes of the $V$. anguillarum strains have been determined previously $(23,38)$. $V$. anguillarum strains of Norwegian origin were isolated and identified as described by Wiik et al. (53). The $V$. salmonicida strains were isolated and identified as described Wiik et al. (51). Aeromonas salmonicida NCMB $1102^{\mathrm{T}}(\mathrm{T}=$ type strain) was used as a fish-pathogenic reference organism.

Growth conditions. The general growth substrates used in this study were tryptone soya broth (Oxoid, Ltd., London, United Kingdom) supplemented with $\mathrm{NaCl}$ at a final concentration of $1.5 \%$ and tryptone soya agar (Oxoid) supplemented with $\mathrm{NaCl}$ at a final concentration of $1.5 \%$. The $V$. salmonicida cultures were incubated at $15^{\circ} \mathrm{C}$ for $48 \mathrm{~h}$, while the remaining cultures were incubated at $22^{\circ} \mathrm{C}$ for 16 to $24 \mathrm{~h}$. All cultures were incubated aerobically with continuous shaking. At the end of the incubation period each of the cultures had reached the late exponential phase. The agar plates were incubated for 1 to 3 days under the same temperature conditions as the broth cultures.

Extraction of RNA. The following three procedures for extraction of RNA were evaluated: (i) the original method of Chomczynski and Sacchi (6); (ii) small-scale variation of the method of Chomczynski and Sacchi (6) (the origina volumes were reduced by a factor of 20); and (iii) the alkaline lysis method of Birnboim and Doly (3), modified so that the nucleic acids were precipitated from the "high-salt" supernatant with 1 volume of isopropanol and the remaining high-molecular-weight RNA was selectively precipitated from the redissolved pellet in sterile, distilled water by adding $10 \mathrm{M}$ ammonium acetate to a fina concentration of $2.5 \mathrm{M}$. After 20 min on ice, the RNA was harvested by centrifugation at 15,800 rpm with an Eppendorf model 5402 centrifuge for $10 \mathrm{~min}$ a $4^{\circ} \mathrm{C}$. The pellet was dried in a Savant Speedvac concentrator and then dissolve in sterile distilled water $(50$ to $100 \mu \mathrm{l})$ to an RNA concentration of $3 \mu \mathrm{g} / \mu \mathrm{l}$.

During the small-scale procedures, cells harvested from tryptone soya aga plates were examined to see if they were as well suited to be sources of $16 \mathrm{~S}$ rRNA as cells harvested from tryptone soya broth were. About $50 \mathrm{mg}$ (wet weight) of cells needed to be harvested from each agar plate.

A comparison of the RNA extraction methods showed that the small-scale variation of the method of Chomczynski and Sacchi (6) was as successful as the original method. Harvesting cells from plates was the strategy that saved the most time. Since the method of Birnboim and Doly (3) was used only rather late in this study, only a few $16 \mathrm{~S}$ rRNAs were isolated by this procedure. This method, however, seemed to save even more time than the small-scale variation of the method of Chomczynski and Sacchi (6); the whole procedure from colony to purified RNA was completed in about $2 \mathrm{~h}$. In addition, the RNA obtained by the 
TABLE 1. Bacterial strains used in this study

\begin{tabular}{|c|c|c|c|c|}
\hline Strain & Source $^{a}$ & Serotype & Host & EMBL accession no. \\
\hline \multicolumn{5}{|l|}{$V$. anguillarum } \\
\hline $\mathrm{NCMB} 6^{\mathrm{T}}$ & NCMB & $\mathrm{O} 2 \mathrm{a}$ & Cod (Gadus morhua) & X16895 \\
\hline NCMB 2130 & NCMB & $\mathrm{O} 2$ & Saithe (Pollachius virens) & X71818 \\
\hline HI 11340 & HI & O2a & $\operatorname{Cod}($ G. morhua $)$ & X71830 \\
\hline HI 11351 & HI & $\mathrm{O} 2 \mathrm{a}$ & Cod (G. morhua) & X71824 \\
\hline HI 11423 & HI & $\mathrm{O} 2 \mathrm{a}$ & Cod (G. morhua) & X71822 \\
\hline HI 4791 & HI & $\mathrm{O} 2 \mathrm{~b}$ & Cod (G. morhua) & X71816 \\
\hline HI 10424 & HI & $\mathrm{O} 2 \mathrm{~b}$ & Cod (G. morhua) & X71833 \\
\hline HI 11336 & $\mathrm{HI}$ & $\mathrm{O} 2 \mathrm{~b}$ & Cod (G. morhua) & X71831 \\
\hline HI 11343 & HI & $\mathrm{O} 2 \mathrm{~b}$ & $\operatorname{Cod}(G$. morhua $)$ & X71827 \\
\hline HI 11349 & HI & $\mathrm{O} 2 \mathrm{~b}$ & $\operatorname{Cod}(G$. morhua $)$ & X71825 \\
\hline NCMB 2129 & NCMB & O1 & Rainbow trout (Oncorhynchus mykis) & X71819 \\
\hline 775 & UO & $\mathrm{O} 1$ & Coho salmon (Oncorhynchus kisutch) & X71814 \\
\hline HI 7400 & HI & $\mathrm{O} 2$ & Atlantic salmon (Salmo salar) & X71815 \\
\hline HI 11331 & HI & $\mathrm{O} 2 \mathrm{a}$ & Turbot (Scophthalmus maximus) & X71832 \\
\hline HI 11341 & HI & O1 & Turbot (Scophthalmus maximus) & X71829 \\
\hline HI 11345 & $\mathrm{HI}$ & O1 & Turbot (Scophthalmus maximus) & X71826 \\
\hline HI 11421 & HI & O1 & Turbot (Scophthalmus maximus) & X71823 \\
\hline HI 11342 & HI & $\mathrm{NT}^{b}$ & Turbot (Scophthalmus maximus) & X71828 \\
\hline HI 11431 & HI & NT & Turbot (Scophthalmus maximus) & X71821 \\
\hline HI 11446 & HI & NT & Turbot (Scophthalmus maximus) & X71820 \\
\hline ATCC 43313 & ATCC & O9 & $\operatorname{Cod}($ G. morhua $)$ & X71817 \\
\hline \multicolumn{5}{|l|}{ V. ordalii } \\
\hline $\operatorname{ATCC} 33509^{\mathrm{T}}\left(=\mathrm{DF}_{3} \mathrm{~K}^{\mathrm{T}}\right)$ & ATCC & & Coho salmon $(O$. kisutch $)$ & X70641 \\
\hline $\operatorname{NCMB} 2167\left(=\mathrm{DF}_{1} \mathrm{~K}\right)$ & NCMB & & Coho salmon $(O$. kisutch $)$ & X71812 \\
\hline MSC2-75 & UO & & Coho salmon (O. kisutch) & X71834 \\
\hline \multicolumn{5}{|l|}{ V. salmonicida } \\
\hline NCMB $2262^{\mathrm{T}}$ & NCMB & & Atlantic salmon (Salmo salar) & X70643 \\
\hline HI 11366-2 & HI & & $\operatorname{Cod}(G$. morhua $)$ & $\mathrm{X} 70638$ \\
\hline HI 11391 & HI & & Atlantic salmon (Salmo salar) & $\times 70639$ \\
\hline HI 651 & HI & & Halibut (Hippoglossus hippoglossus) & X71811 \\
\hline PT2 & UT & & $\operatorname{Cod}(G$. morhua $)$ & $\mathrm{X} 70637$ \\
\hline V. iliopiscarius PS1 & UT & & Herring (Clupea harengus) & $\times 70636$ \\
\hline \multicolumn{5}{|l|}{$V$. fischeri } \\
\hline NCMB $1281^{\mathrm{T}}$ & NCMB & & Seawater & $\mathrm{X} 70640$ \\
\hline NCMB 1274 & NCMB & & Merluza (Merluccius vulgaris) & $\mathrm{X} 71813$ \\
\hline$V$. damsela $\mathrm{NCMB} 2184^{\mathrm{T}}$ & NCMB & & Damsel fish (Chromis punctipinnis) & $X 71835$ \\
\hline$V$. pelagius NCMB $1900^{\mathbf{T}}$ & NCMB & & Seawater & $\mathrm{X} 70642$ \\
\hline $\begin{array}{l}\text { A. salmonicida } \mathrm{NCMB} \\
1102^{\mathrm{T}}\end{array}$ & NCMB & & Atlantic salmon (Salmo salar) & X71836 \\
\hline
\end{tabular}

a ATCC, American Type Culture Collection; HI, Havforskningsinstituttet; NCMB, National Collection of Marine Bacteria; UO, University of Oregon; UT, Universitetet i Tromsø.

${ }^{b}$ NT, not typeable.

method of Birnboim and Doly (3) was as good as the RNA obtained by the method of Chomczynski and Sacchi (6) as a template for the enzyme reverse transcriptase. It should be noted in this context that reverse transcriptase sequencing of rRNA has been almost completely replaced by the PCR method, which is often followed by automatic sequence analysis.

Reverse transcriptase sequencing of $16 \mathrm{~S}$ rRNA. For the sequence analysis we used previously described methods $(24,46)$. Almost complete 16S rRNA sequences were determined for nine bacterial strains. Primers (14) were located around positions 350,530,700,900,1100, 1200, and 1400 (Escherichia coli nomenclature). In addition, we used two primers having the following sequences (E. coli $3^{\prime}$ positions indicated): GGCCCGAAGGTCCCCCT (position 215) and TTACGACTTCACCCCAGT (position 1500). On the basis of the results of this analysis, the remaining strains were investigated by using primers 215,530 , and 1100 .

Terminal deoxynucleotidyl transferase (Boehringer Mannheim $\mathrm{GmbH}$ ) was used as described previously (8). The products of the sequencing reactions were separated as described by Embley et al. (14) with an LKB sequencing apparatus.
$16 S$ rRNA data analysis. The $16 S$ rRNA sequences were manually aligned with the sequences in a database containing data for Vibrio strains and related taxa $(10,32)$. The number of positions included in the analysis depended on the size of the shortest sequence in the database. Pairwise evolutionary distances (expressed as estimated number of changes per 100 nucleotides) were computed from percentages of similarity by using the correction of Jukes and Cantor (21). Phylogenetic trees were constructed from the distance matrices by the algorithm of De Soete (9).

Physiological and serological characterization. Only the phenotypic characteristics of $V$. salmonicida $\mathrm{HI} 651$ are presented below, as the remaining strains which we studied have been described elsewhere. The growth of strain HI 651 in the presence of $\mathrm{NaCl}$ was determined in tryptone soya broth and on tryptone soya agar amended with $\mathrm{NaCl}$ at final concentrations of $0.5,1.5,4.0,6.0$, and $8.0 \%$. The cultures were incubated at $15^{\circ} \mathrm{C}$ and observed for 7 days. The ability of strain $\mathrm{HI} 651$ to grow at different temperatures was determined by incubating cultures at $4,10,15,20,25$, and $30^{\circ} \mathrm{C}$. The growth medium used was nutrient agar (Oxoid) supplemented with $5 \%$ citrated sheep blood and $\mathrm{NaCl}$ at a final con- 


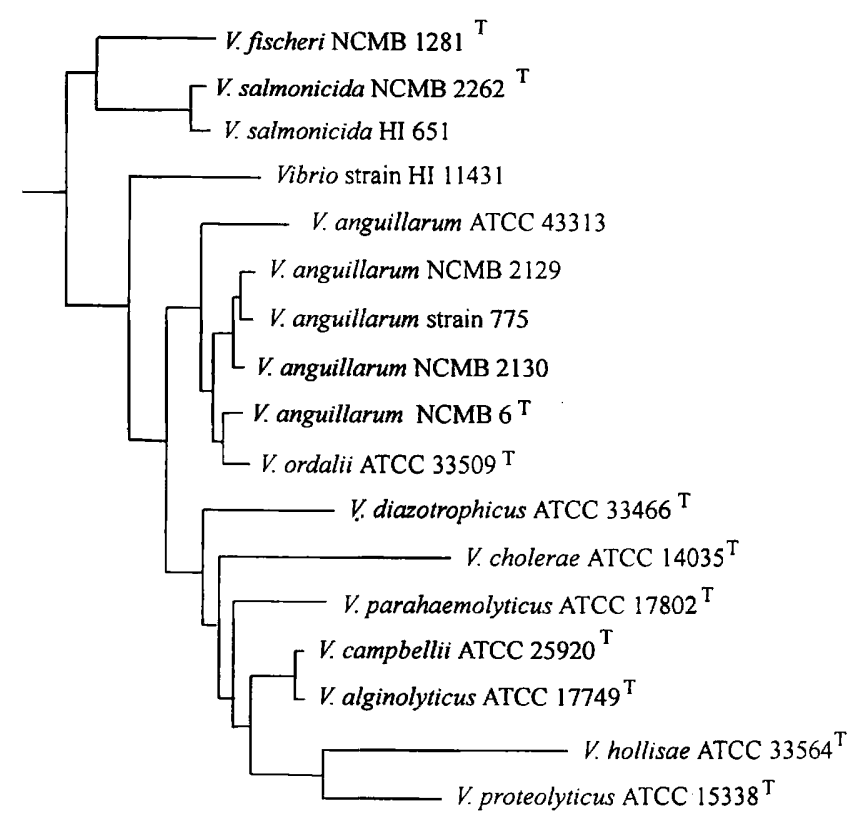

$2.5 \%$

FIG. 1. Distance tree derived from the almost complete 16S rRNA sequences of fish-pathogenic vibrios and Vibrio reference strains. The tree was constructed from a distance matrix by using the algorithm of De Soete (9). The distance matrix was derived from the similarity matrix (Table 2) by using the correction of Jukes and Cantor (21). A. salmonicida was used as the root organism. $\mathrm{Bar}=2.5 \%$ sequence divergence.

centration of $1.5 \%$ (blood agar). The agar plates were observed for 1 week Hemolysis was determined by examining growth on blood agar plates.

The fermentative ability of strain HI 651 was determined by using the API 50CH (API 50CHE medium) system (API Systems, S.A., La Balme Les Grottes,
Montalieu Vercieu, France); sterile $\mathrm{NaCl}$ was added to the fuid to a final concentration of $1.5 \%$. Additional biochemical activities were determined with API $20 \mathrm{E}$ galleries $(70 \%$ sterile seawater was used as the medium). The galleries were incubated at $15^{\circ} \mathrm{C}$, and results were determined after $48 \mathrm{~h}$ of incubation.

Rabbit polyclonal antisera against formalin-killed cells of strains of $V$. salmonicida and different serogroups of $V$. anguillanum were prepared by the methods of Oeding (29). Serotyping was performed by using an enzyme-linked immunosorbent assay as described by Wiik et al. (53).

Nucleotide sequence accession numbers. The nucleotide sequences of the strains included in this study have been deposited in the EMBL Data Library, Heidelberg, Germany, under the accession numbers shown in Table 1.

\section{RESULTS}

Phylogenetic relationships based on an analysis of almost complete 16S rRNA sequences. The almost complete sequences obtained from eight strains of four Vibrio species and the type strain of $A$. salmonicida were analyzed. A thorough phylogenetic analysis of aeromonads, including $A$. salmonicida, has been published recently (39), and the results of this analysis supported the finding that there is moderate degree of relatedness between members of the family Vibrionaceae and members of the family Aeromonadaceae. Only data for sequence positions that were known for all of the strains used in the analysis were included. Binary homology values, which were based on an analysis of 1,270 nucleotides, were determined for type strains of eight Vibrio species $(10,11,50$; this study) and six additional strains identified as either $V$. salmonicida or $V$. anguillarum. The dendrogram of relationships (Fig. 1) indicates that Vibrio fischeri and the two strains of $V$. salmonicida studied are very similar to one another. A second group is formed by strains of $V$. anguillarum and the type strain of $V$. ordalii, which is almost identical to the type strain of $V$. anguillarum (level of sequence similarity, 99.4\%). Most $V$. anguillarum strains exhibit high levels of sequence similarity to one another (98.2 to $99.9 \%$ ) (Tables 2 and 3); only $V$. anguillanum HI 11342, HI 11431, HI 11446, and ATCC 43313 are more distantly related (levels of sequence similarity, 95.2 to 97.6\%). The other Vibrio species, including those whose sequences have been published previously (10) and Vibrio chol-

TABLE 2. Similarity matrix based on a comparison of almost complete $16 \mathrm{~S}$ rRNA sequences

\begin{tabular}{|c|c|c|c|c|c|c|c|c|c|c|c|c|c|c|c|c|c|}
\hline \multirow[b]{2}{*}{ Strain } & \multicolumn{17}{|c|}{ \% Similarity to: } \\
\hline & 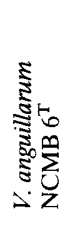 & 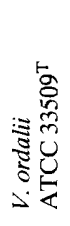 & 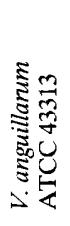 & 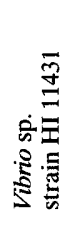 & 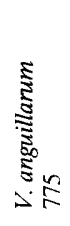 & 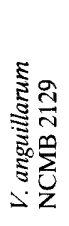 & 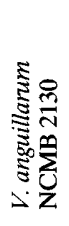 & 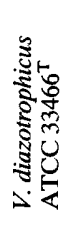 & 苦 & 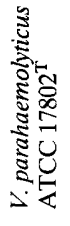 & 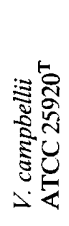 & 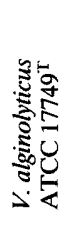 & 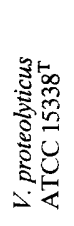 & 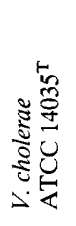 & 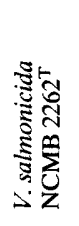 & 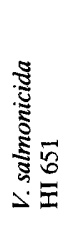 & 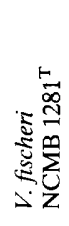 \\
\hline V. ordalii ATCC $33509^{\mathbf{T}}$ & 99.4 & & & & & & & & & & & & & & & & \\
\hline V. anguillarum ATCC 43313 & 98.6 & 98.2 & & & & & & & & & & & & & & & \\
\hline Vibrio sp. strain HI 11431 & 97.0 & 96.9 & 96.9 & & & & & & & & & & & & & & \\
\hline V. anguillarum 775 & 99.3 & 98.7 & 98.0 & 97.5 & & & & & & & & & & & & & \\
\hline$V$. anguillanum NCMB 2129 & 99.2 & 98.8 & 98.1 & 97.6 & 99.9 & & & & & & & & & & & & \\
\hline V. anguillarum NCMB 2130 & 99.2 & 98.8 & 98.2 & 97.8 & 99.7 & 99.8 & & & & & & & & & & & \\
\hline V. diazotrophicus ATCC $33466^{\mathrm{T}}$ & 97.3 & 97.4 & 96.1 & 95.5 & 97.0 & 97.1 & 97.1 & & & & & & & & & & \\
\hline$V$. hollisae ATCC 33564 & 93.0 & 92.9 & 92.3 & 91.8 & 93.0 & 93.0 & 93.0 & 93.3 & & & & & & & & & \\
\hline V. parahaemolyticus ATCC $17802^{\mathrm{T}}$ & 96.8 & 96.6 & 96.0 & 95.5 & 96.8 & 96.9 & 96.9 & 96.9 & 93.5 & & & & & & & & \\
\hline V. campbellii ATCC $25920^{\mathrm{T}}$ & 97.3 & 97.1 & 96.5 & 96.0 & 97.3 & 97.4 & 97.4 & 97.3 & 94.2 & 98.4 & & & & & & & \\
\hline$V$. alginolyticus ATCC $17749^{\mathrm{T}}$ & 97.3 & 97.1 & 96.5 & 95.9 & 97.3 & 97.4 & 97.4 & 97.4 & 94.2 & 98.3 & 99.9 & & & & & & \\
\hline V. proteolyticus ATCC $15338^{\mathrm{T}}$ & 95.3 & 95.1 & 94.5 & 93.9 & 95.3 & 95.4 & 95.4 & 95.2 & 94.7 & 97.1 & 97.5 & 97.6 & & & & & \\
\hline$V$. cholerae ATCC $14035^{\mathrm{T}}$ & 94.3 & 94.5 & 93.8 & 93.6 & 94.4 & 94.5 & 94.3 & 93.9 & 92.2 & 94.4 & 95.0 & 95.0 & 93.2 & & & & \\
\hline V. salmonicida NCMB $2262^{\mathrm{T}}$ & 96.4 & 96.3 & 96.0 & 96.3 & 95.8 & 95.9 & 95.9 & 94.6 & 91.9 & 94.5 & 95.3 & 95.3 & 94.0 & 94.7 & & & \\
\hline$V$. salmonicida HI 651 & 96.1 & 96.0 & 95.7 & 96.4 & 95.5 & 95.6 & 95.6 & 94.6 & 91.8 & 94.5 & 95.3 & 95.3 & 93.8 & 94.7 & 99.7 & & \\
\hline$V$. fisheri $\mathrm{NCMB} 1281^{\mathrm{T}}$ & 95.7 & 95.6 & 95.5 & 95.8 & 95.7 & 95.8 & 96.0 & 94.2 & 91.3 & 94.7 & 95.4 & 95.4 & 93.9 & 94.7 & 97.0 & 97.3 & \\
\hline A. salmonicida NCMB $1102^{\mathrm{T}}$ & 90.1 & 90.4 & 90.0 & 89.7 & 89.6 & 89.7 & 89.7 & 89.6 & 88.0 & 90.0 & 90.2 & 90.1 & 89.0 & 89.6 & 91.2 & 91.1 & 90.7 \\
\hline
\end{tabular}


TABLE 3. Similarity matrix based on partial $16 \mathrm{~S}$ rRNA sequences comprising 560 nucleotides

\begin{tabular}{|c|c|c|c|c|c|c|c|c|c|c|c|c|c|c|c|c|c|c|c|c|c|}
\hline \multirow[b]{2}{*}{ Strain } & \multicolumn{21}{|c|}{$\%$ Similarity to: } \\
\hline & 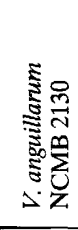 & 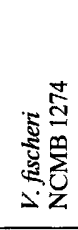 & 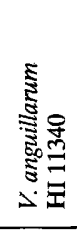 & 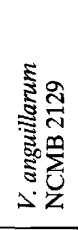 & 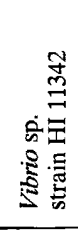 & 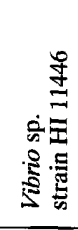 & 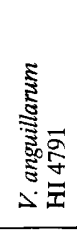 & 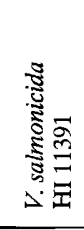 & 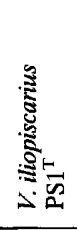 & 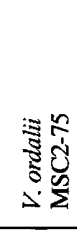 & 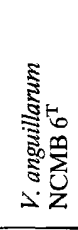 & 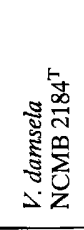 & 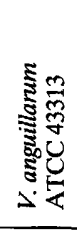 & 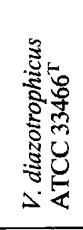 & 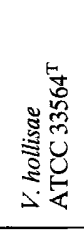 & 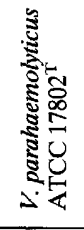 & 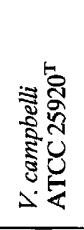 & 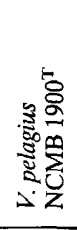 & 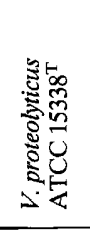 & 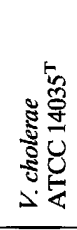 & 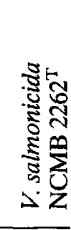 \\
\hline V. fischeri NCMB 1274 & 94.1 & & & & & & & & & & & & & & & & & & & & \\
\hline$V$. anguillarum HI 11340 & 99.8 & 94.3 & & & & & & & & & & & & & & & & & & & \\
\hline V. anguillarum NCMB 2129 & 99.8 & 93.8 & 99.6 & & & & & & & & & & & & & & & & & & \\
\hline Vibrio sp. strain HI 11342 & 96.0 & 93.6 & 95.8 & 95.8 & & & & & & & & & & & & & & & & & \\
\hline Vibrio sp. strain HI 11446 & 95.2 & 93.6 & 94.9 & 94.9 & 98.7 & & & & & & & & & & & & & & & & \\
\hline V. anguillarum HI 4791 & 99.3 & 93.4 & 99.1 & 99.1 & 95.4 & 94.5 & & & & & & & & & & & & & & & \\
\hline V. salmonicida HI 11391 & 93.6 & 99.1 & 93.8 & 93.4 & 93.2 & 93.2 & 93.0 & & & & & & & & & & & & & & \\
\hline V. iliopiscarius PS1 $^{\mathrm{T}}$ & 93.0 & 95.8 & 93.2 & 92.7 & 93.0 & 91.6 & 92.3 & 95.4 & & & & & & & & & & & & & \\
\hline V. ordalii MSC2-75 & 93.8 & 92.1 & 93.6 & 93.6 & 93.4 & 93.4 & 93.2 & 91.6 & 91.4 & & & & & & & & & & & & \\
\hline V. anguillarum $\mathrm{NCMB} 6^{\mathrm{T}}$ & 98.9 & 93.6 & 99.1 & 98.7 & 94.9 & 94.1 & 98.2 & 94.5 & 92.5 & 93.2 & & & & & & & & & & & \\
\hline$V$. damsela NCMB $2184^{\mathrm{T}}$ & 97.9 & 93.3 & 98.2 & 98.6 & 94.0 & 93.4 & 97.5 & 93.6 & 91.9 & 92.8 & 99.2 & & & & & & & & & & \\
\hline$V$. anguillarum ATCC 43313 & 97.6 & 93.0 & 97.8 & 97.4 & 93.8 & 93.8 & 96.9 & 93.8 & 91.9 & 92.3 & 98.7 & 98.2 & & & & & & & & & \\
\hline V. diazotrophicus ATCC $33466^{T}$ & 95.4 & 91.2 & 95.4 & 95.2 & 92.1 & 91.2 & 94.7 & 92.1 & 90.3 & 91.9 & 96.0 & 95.7 & 94.7 & & & & & & & & \\
\hline$V$. hollisae ATCC $33564^{\mathrm{T}}$ & 93.6 & 91.9 & 93.4 & 93.4 & 92.7 & 93.2 & 93.0 & 92.3 & 89.9 & 94.1 & 93.6 & 93.1 & 93.2 & 92.7 & & & & & & & \\
\hline V. parahaemolyticus ATCC $17802^{\mathrm{T}}$ & 94.9 & 92.7 & 94.9 & 94.7 & 95.4 & 94.3 & 94.3 & 92.3 & 92.3 & 94.1 & 94.5 & 94.0 & 93.6 & 93.2 & 93.8 & & & & & & \\
\hline V. campbellii ATCC $25920^{\mathrm{T}}$ & 95.4 & 93.4 & 95.4 & 95.2 & 94.5 & 94.1 & 94.7 & 93.0 & 92.3 & 94.1 & 94.9 & 94.6 & 94.1 & 93.6 & 94.1 & 97.4 & & & & & \\
\hline V. pelagius $\mathrm{NCMB} 1900^{\mathrm{T}}$ & 95.2 & 93.2 & 95.2 & 94.9 & 95.2 & 94.7 & 94.5 & 92.7 & 91.6 & 95.8 & 94.7 & 94.5 & 94.1 & 93.2 & 93.8 & 97.8 & 97.4 & & & & \\
\hline V. proteolyticus ATCC $15338^{\mathrm{T}}$ & 94.5 & 92.3 & 94.5 & 94.3 & 94.3 & 94.1 & 93.8 & 91.9 & 91.2 & 93.4 & 94.1 & 93.7 & 93.2 & 92.7 & 94.7 & 97.6 & 98.9 & 96.9 & & & \\
\hline V. cholerae ATCC $14035^{\mathrm{T}}$ & 94.7 & 91.4 & 94.9 & 94.9 & 92.3 & 91.4 & 94.1 & 90.8 & 91.0 & 92.5 & 94.5 & 94.4 & 93.4 & 93.0 & 91.6 & 91.9 & 92.3 & 91.9 & 91.6 & & \\
\hline V. salmonicida NCMB $2262^{\mathrm{T}}$ & 93.6 & 99.1 & 93.8 & 93.4 & 93.2 & 93.2 & 93.0 & 100.0 & 95.4 & 91.6 & 94.5 & 93.9 & 93.8 & 92.1 & 92.3 & 92.3 & 93.0 & 92.7 & 91.9 & 92.1 & \\
\hline V. fischeri NCMB $1281^{\mathrm{T}}$ & 93.2 & 95.2 & 93.4 & 93.0 & 93.6 & 92.7 & 92.5 & 94.3 & 93.8 & 94.5 & 92.7 & 92.3 & 91.9 & 91.0 & 91.9 & 93.6 & 93.6 & 94.7 & 93.0 & 92.3 & 94.3 \\
\hline
\end{tabular}




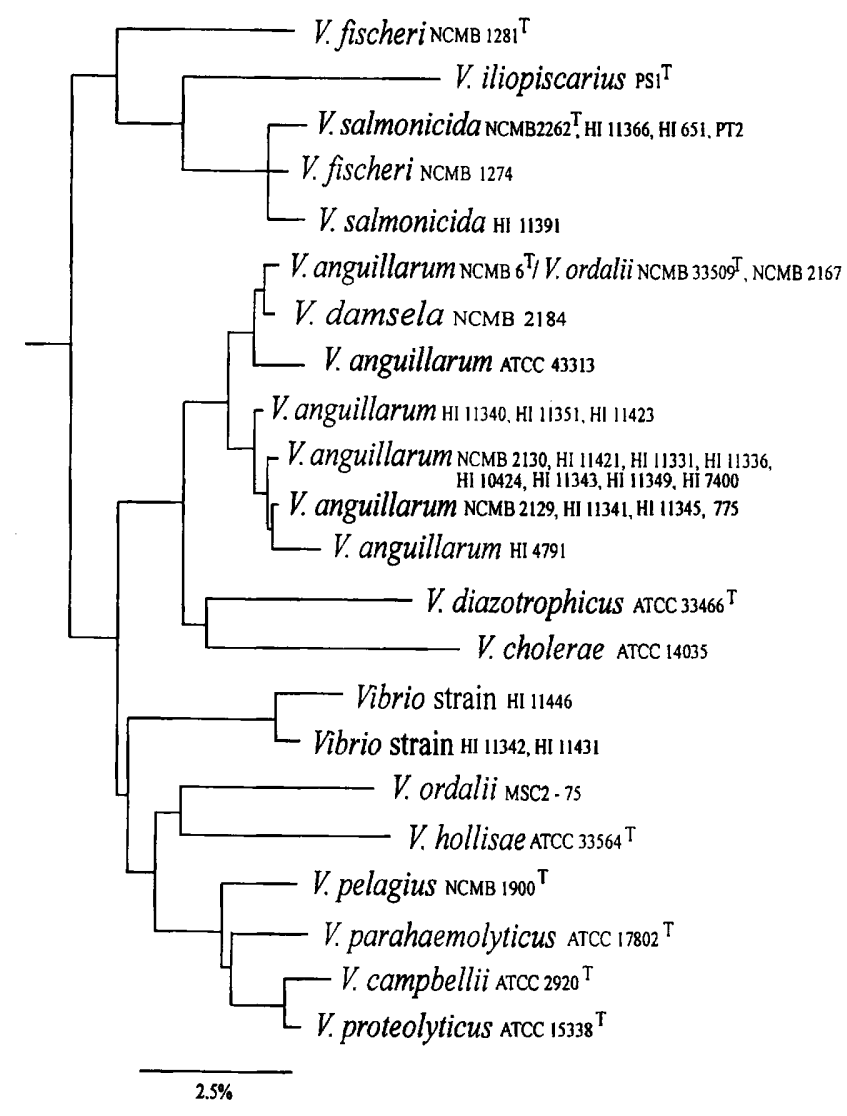

FIG. 2. Distance tree derived from partial $16 \mathrm{~S}$ rRNA sequences (560 nucleotides) of fish-pathogenic vibrios and Vibrio reference strains. The tree was constructed from a distance matrix by using the algorithm of De Soete (9). The distance matrix was computed from the similarity matrix (Table 3 ) by using the correction of Jukes and Cantor (21). A. salmonicida was used as the root organism. Bar $=2.5 \%$ sequence divergence.

erae (11), form several groups, and only Vibrio campbellii and Vibrio alginolyticus appear to be closely related (level of sequence similarity, $99.9 \%$ ). A comparison of the dendrogram shown in Fig. 1 with the dendrogram published previously (10), for which a different treeing algorithm was used and which included fewer stains, showed that the trees are similar with respect to the composition of the Vibrio core species (V. campbellii, V. alginolyticus, Vibrio parahaemolyticus, and Vibrio proteolyticus) and with respect to the position of Vibrio outskirt organisms, such as $V$. anguillarum and Vibrio diazotrophicus. The major difference between the two trees is the position of Vibrio hollisae, which clustered with the Vibrio core organisms in our study. The positions of strains of $V$. ordalii, $V$. salmonicida, and $V$. fischeri indicate that none of these organisms belongs to the core group of the genus Vibrio.

On the basis of variable $16 \mathrm{~S}$ rRNA sequence regions which differentiated similar taxa, we selected three regions for further phylogenetic analysis. The isolates which we investigated had been identified previously by traditional taxonomic methods as strains of $V$. anguillarum and $V$. salmonicida. The results of an analysis of the selected regions, which contained a total of 560 nucleotides, were very similar to the results of the analysis based on almost complete sequences (Fig. 1 and 2). This was most obvious in the clustering of $V$. fischeri and $V$. salmonicida, in the clustering of $V$. anguillarum and $V$. ordalii, and in the composition of the Vibrio core species, which included the type strain of Vibrio pelagius. The results of our phylogenetic study confirmed the finding that $V$. anguillarum and $V$. pelagius should not be placed in the same genus (22). When the results of this analysis were compared with the results of the analysis of almost complete sequences, $V$. hollisae changed its position and clustered with a strain identified as a member of $V$. ordalii (Fig. 2).

Our comparative $16 \mathrm{~S}$ rRNA analysis confirmed that all of the strains preliminarily identified as $V$. anguillarum except strains HI 11342, HI 11431, HI 11446, and ATCC 43313 are closely related to each other and should be considered conspecific. These strains could be divided into groups. The main group consisted of serotype $\mathrm{O} 1$ and $\mathrm{O} 2$ strains isolated from Atlantic salmon, rainbow trout, turbot, cod, and saithe (Fig. 2 and Table 1). Serotype O2a strains isolated from cod formed one subgroup, while serotype O2b strains isolated from cod clustered with serotype $\mathrm{O} 2 \mathrm{a}$ and $\mathrm{O} 1$ strains isolated from turbot and salmon. Thus, there was not an obvious correspondence among the subgroups based on host specificity, serotype, and phylogenetic position. The other distinct group was represented by the type strain, strain NCMB 6 . On the basis of the $16 \mathrm{~S}$ rRNA sequences compared, this strain could not be distinguished from strains identified as $V$. ordalii (ATCC $33509^{\mathrm{T}}$ and NCMB 2167). An organism that is very closely related to these strains is $V$. damsela NCMB $2184^{\mathrm{T}}$ (level of sequence similarity, 99.2\%). Strain MSC2-75, which was previously identified as $V$. ordalii $(40,41)$, was far removed from the other $V$. ordalii strains (Fig. 2) and clustered with $V$. hollisae.

Three strains identified as $V$. anguillarum were only moderately related to the type strain of this species (levels of sequence difference, 3 to $5 \%$ ). The levels of similarity between strain HI 11446 and strains HI 11342 and HI 11431 were as great as the levels of similarity between members of the subgroups containing the authentic $V$. anguillarum strains.

The results of our comparative 16S rRNA analysis justified the status of $V$. salmonicida as a distinct species. Despite diverging biochemically from the original species description (13) by being able to ferment galactose, cellobiose, and betagentiobiose, as well as by being able to produce lysine decarboxylase and to reduce nitrate to nitrite, strain $\mathrm{HI}$ 651, which was isolated from diseased halibut, exhibited a high level of sequence similarity to the type strain of $V$. salmonicida (Table 4). Except for the fact that strain $\mathrm{HI} 651$ is able to grow in the presence of a maximum $\mathrm{NaCl}$ concentration of $6 \%$ and has a maximum growth temperature of $25^{\circ} \mathrm{C}$ (the corresponding values for NCMB $2262^{\mathrm{T}}$ are $4 \% \mathrm{NaCl}$ and $20^{\circ} \mathrm{C}$ ), strains $\mathrm{HI} 651$ and NCMB $2262^{\mathrm{T}}$ exhibit similar growth patterns with respect to $\mathrm{NaCl}$ concentrations and temperatures. Strain $\mathrm{HI} 651$ exhibited the same serological pattern as the type strain of $V$. salmonicida. Strain PT2, which was isolated from the intestines of healthy cod, is phylogenetically almost indistinguishable from $V$. salmonicida strains (33). This strain does not seem to have the same serological pattern as strains NCMB $2262^{\mathrm{T}}$ and HI 651 (37). Biochemical and distant matrix data for strains $V$. salmonicida NCMB $2262^{\mathrm{T}}$, HI 651 , and PT2 are shown in Table 4.

$V$. fischeri NCMB 1274 and $V$. salmonicida HI 11391 are closely related to the type strain of $V$. salmonicida and can be considered members of this species. The species Vibrio iliopiscarius has recently been described for a group of gut vibrios (33).

\section{DISCUSSION}

In this study, we performed a comparative 16S rRNA analysis with selected fish-pathogenic vibrios and some nonpathogenic vibrios. The bacterial strains were selected with care on 
TABLE 4. Differentiating biochemical characteristics and distance matrix data for $V$. salmonicida and $V$. salmonicida-like strains

\begin{tabular}{|c|c|c|c|c|c|c|c|c|c|}
\hline \multirow[b]{2}{*}{ Taxon } & \multirow{2}{*}{$\begin{array}{c}\text { Lysine } \\
\text { decarboxylase } \\
\text { activity }\end{array}$} & \multirow[b]{2}{*}{$\begin{array}{l}\text { Reduction of } \\
\mathrm{NO}_{3} \text { to } \mathrm{NO}_{2}\end{array}$} & \multicolumn{3}{|c|}{ Utilization of: } & \multirow{2}{*}{$\begin{array}{l}\text { Maximum } \\
\mathrm{NaCl} \\
\text { concn }(\%)\end{array}$} & \multirow[b]{2}{*}{$\begin{array}{l}\text { Maximum } \\
\text { temp }\left({ }^{\circ} \mathrm{C}\right)\end{array}$} & \multicolumn{2}{|c|}{$\%$ Similarity to: } \\
\hline & & & Galactose & Cellobiose & $\beta$-Gentiobiose & & & $\begin{array}{c}\text { Strain NCMB } \\
2262^{\mathrm{T}}\end{array}$ & $\begin{array}{c}\text { Strain } \\
\text { HI } \\
651\end{array}$ \\
\hline Strain NCMB $2262^{\mathrm{T}}$ & $-a$ & - & - & - & - & 4 & 20 & & \\
\hline Strain HI 651 & + & + & + & + & + & 6 & 25 & 99.4 & \\
\hline Strains represented by PT $2^{b}$ & + & + & $\mathrm{d}$ & $\mathrm{d}$ & d & 5 & 22 & 99.4 & 99.8 \\
\hline
\end{tabular}

${ }^{a}-$, negative; + , positive; $\mathrm{d}, 11$ to $89 \%$ of the strains are positive.

${ }^{b}$ Data from reference 33 .

the basis of their biochemical $(38,51,53)$, serological $(23,38)$, genetic (51-53), and host-specific (38) properties. Such a strategy made it possible to compare the results of the 16S rRNA analysis with results based on other classification systems. The evolutionary relationships determined in this study agree in many respects with the current taxonomy of fish-pathogenic vibrios. However, our $16 \mathrm{~S}$ rRNA analysis also revealed a few unexpected phylogenetic relationships.

The three $16 \mathrm{~S}$ rRNA regions sequenced by using primers 215 (positions 1 to 186), 530 (positions 301 to 504), and 1100 (positions 925 to 1088) turned out to be specifically suitable for determining phylogenetic relationships among the vibrios. The region from position 925 to position 1088 (the most variable portion was between positions 987 and 1041) allowed us to differentiate Vibrio species from each other and from members of other genera. The region from position 301 to position 504 (the most variable portion was between positions 451 and 477) allowed us to differentiate Vibrio species from each other and to some degree to differentiate strains belonging to the same species. The region from position 1 to position 186 (the most variable portion was between positions 60 and 100) was found to be useful for intraspecies differentiation. The region from position 330 to position 500 has been used previously in phylogenetic studies of the genus Vibrio $(10,22,35)$. Because of the limited overlap between the 16S rRNA regions used for analysis (restricted to the region from position 308 to position 504 ), the recently published $16 \mathrm{~S}$ rRNA sequences of Vibrio species (22) were not included for comparison in this study. In addition, the sequences described by Kita-Tsukamoto et al. (22) contain many positions with ambiguous bases, and the omission of these positions from the analysis would have reduced the number of comparable nucleotides to an unacceptably low number.

In spite of being preliminarily identified as $V$. anguillarum, strains HI 11342, HI 11431, HI 11446, and ATCC 43313 diverge evolutionarily from the other $V$. anguillarum strains. This finding is consistent with the fact that these strains can be separated clearly from the other strains identified as $V$. anguillarum both serologically (Table 1) and biochemically (37).

The 16S rRNAs of strains NCMB $6^{\mathrm{T}}\left(=\right.$ ATCC $\left.19264^{\mathrm{T}}\right)$ and ATCC $43313(=1247 / 1)$ have been partially sequenced (position 413 through position 515) previously by Rehnstam et al. (35). However, since V. anguillarum was the only Vibrio species included in the study of Rehnstam et al. (35) and because only about 100 nucleotides were compared, an accurate systematic relationship between strains ATCC 43313 and NCMB $6^{\mathrm{T}}$ could not be determined. According to the results of our study, strain ATCC 43313, which was identified as a $V$. anguillarum serotype O9 strain, (43), is as different from NCMB $6^{\mathrm{T}}$ (level of sequence similarity, $89 \%$ ) as type strain NCMB 2262 of $V$. salmonicida is (level of sequence similarity, $89 \%$ ). The distant relationship between strains ATCC 43313 and NCMB $6^{\mathrm{T}}$ has been confirmed by phenotypic comparisons (37). Our results agree with those of Martinez-Picado et al. (28), who showed that $V$. anguillarum ATCC 43313 (serovar O9) is not recognized by an oligonucleotide probe for $V$. anguillarum $16 \mathrm{~S}$ rRNA. Serovar O9 and O10 strains were found to have sequences in the V3 region which clearly differed from the sequences of strains belonging to the other serovars (28). In conclusion, the classification of strain ATCC 43313 as a strain of $V$. anguillarum should be confirmed by DNA-DNA hybridization experiments.

According to our 16S rRNA sequence data, type strain NCMB 6 (= ATCC 19264) paradoxically does not seem to be typical of the species $V$. anguillarum. This result is consistent with the results of our previous DNA-DNA homology studies (52) and also with the results of studies which showed that strain NCMB $6^{\mathrm{T}}$ differs from the majority of the $V$. anguillarum strains that have been characterized with respect to biochemical characteristics and also with respect to plasmid pattern (53).

A fish-pathogenic vibrio designated $V$. ordalii (41) has been isolated in North America and Japan $(19,30,31)$. The results of our $16 \mathrm{~S}$ rRNA analysis show that the type strain of $V$. ordalii, strain ATCC $33509^{\mathrm{T}}\left(=\mathrm{DF}_{3} \mathrm{~K}^{\mathrm{T}}\right)$, and strain NCMB $2167(=$ $\left.\mathrm{DF}_{1} \mathrm{~K}\right)$ are phylogenetically almost indistinguishable from type strain NCMB 6 of $V$. anguillarum. Strains ATCC $33509^{\mathrm{T}}$, NCMB 2167, and NCMB $6^{\mathrm{T}}$ have nearly identical DNA G + C contents (44 mol\% according to Schiewe et al. [41] and 47 mol\% according to Wiik and Egidius [52]). Recently, Larsen et al. (25) found that all $V$. ordalii strains included in their study reacted with $\mathrm{O} 2 \mathrm{a}$ antiserum prepared against $V$. anguillarum. On the basis of these results the validity of the species $V$. ordalii (41) needs to be reconfirmed by DNA-DNA hybridization.

Strain MSC2-75, which originally was identified as V. ordalii, is only distantly related to strains ATCC $33509^{\mathrm{T}}$ and NCMB 2167 , as shown by the $16 \mathrm{~S}$ rRNA analysis results. These results are consistent with the results of our previous DNA-DNA hybridization studies which revealed a low level of DNA homology between strains NCMB 2167 and MSC2-75 (52). However, strains NCMB 2167 and MSC2-75 produce the same plasmid pattern $(40,51)$. The pathogenicity of these bacterial strains may be encoded by genes on the plasmid, and this may be the reason why they have been associated with the same fish disease. According to the 16S rRNA sequence data, strain MSC2-75 cannot be placed in any of the other Vibrio species included in this study.

Both $V$. ordalii and type strain NCMB 2184 of $V$. damsela (26) seem to be phylogenetically very closely related to the type strain of $V$. anguillarum. On the basis of our $16 \mathrm{~S}$ rRNA results these strains can be considered members of the same species. On the basis of the results of the partial 16S rRNA analysis of Kita-Tsukamoto et al. (22), however, the type strains of $V$. anguillarum and $V$. damsela are not similar enough to justify 
placement in the same species. The results of comparative $5 \mathrm{~S}$ rRNA analysis have shown that the type strains of $V$. anguillarum and $V$. damsela are fairly closely related (27). However, these strains were not included in the same species by MacDonell and Colwell but rather were placed in the new genus Listonella, which includes the species Listonella anguillara $(V$. anguillarum), Listonella damsela ( $V$. damsela), and Listonella pelagia ( $V$. pelagius) (27). $V$. damsela and $V$. anguillarum have similar biochemical properties $(36,53)$. For both $V$. damsela and $V$. anguillarum, the main clinical symptoms of affected moribund fish are lethargy, hemorrhages at the base of the tail, and extensive ulcerative lesions (36). These taxa also have several host species in common. The $\mathrm{G}+\mathrm{C}$ contents of $V$. anguillarum and $V$. damsela have been determined to be 46 to $47 \mathrm{~mol} \%$ (52) and $43 \mathrm{~mol} \%$ (26), respectively. Different methods were used to determine the $\mathrm{G}+\mathrm{C}$ contents of $V$. anguillarum and $V$. damsela, and this may explain the disparity in the $\mathrm{G}+\mathrm{C}$ content values.

Until now, $V$. salmonicida has been considered a biochemically very homogeneous species that consists of strains which are isolated from salmonid fish suffering from cold-water vibriosis $(13,44,52)$. Occasionally, this bacterium, which has been assigned a maximum growth temperature of $20^{\circ} \mathrm{C}$, has also caused disease in cod (44). By performing a comparative $16 \mathrm{~S}$ rRNA sequence analysis, we found that strain $\mathrm{HI} 651$, which was isolated from diseased halibut fry, is closely related to traditional $V$. salmonicida strains, which is consistent with the identical serotypes of these organisms. Strain HI 651, however, differs biochemically from other isolates of $V$. salmonicida.

In addition to strain HI 651, the apparently nonpathogenic strain PT2, which is indigenous to the intestines of marine fish, exhibits a close phylogenetic relationship to the $V$. salmonicida group (33). Strain PT2 clearly differs from typical $V$. salmonicida strains in its biochemical properties and also by the fact that it is able to grow at higher temperatures (33). This strain, however, has a DNA G+C content which is nearly identical to that of typical $V$. salmonicida strains $(33,52)$. On the basis of our new data for $V$. salmonicida, we suggest that the species description should be extended to include strains represented by strains $\mathrm{HI} 651$ and PT2.

In this work, two groups of bacteria indigenous to the intestines of marine fish were represented by strains PT2 and PS1 ${ }^{\mathrm{T}}$. While strain PT2, which was isolated from cod, should probably be included in the species $V$. salmonicida, strain PS1, which was isolated from herring, has recently been designated the type strain of the new species $V$. iliopiscarius (33). This new species is quite closely related to $V$. salmonicida and $V$. fischer $\left(\right.$ NCMB 1281 ${ }^{\mathrm{T}}$ ) (Fig. 2). The DNA base compositions of these three species range from 39 to $42 \mathrm{~mol} \% \mathrm{G}+\mathrm{C}$.

Although strain NCMB 1274 has been identified as $V$. fischeri, our 16S rRNA analysis results indicate that it does not belong to $V$. fischeri as represented by type strain NCMB 1281 . On the other hand, strain NCMB 1274 is more closely related phylogenetically to the $V$. salmonicida group.

In conclusion, comparative $16 \mathrm{~S}$ rRNA sequence analysis seems to be suitable for identification and differentiation of fish-pathogenic vibrios. The evolutionary relationships determined in our study in many respects are consistent with the current taxonomy, but interesting unexpected phylogenetic relationships were also revealed. Further studies should be performed in order to compare systematically results based on different classification systems.

\section{ACKNOWLEDGMENTS}

We thank Kjell Arne Hoff, Vigdis Torsvik, and Rogaland Research (RF) for support.
This work was supported by a grant from the Norwegian Council of Fisheries Research (NFFR).

\section{REFERENCES}

1. Baumann, P., S. S. Bang, and L. Baumann. 1978. Phenotypic characterization of Beneckea anguillara biotypes I and II. Curr. Microbiol. 1:85-88.

2. Bergman, A. M. 1909. Die roten Beulenkrankheit des Aals. Ber. K. Bayer Versuchsstn. 2:10-54

3. Birnboim, H. C., and J. Doly. 1979. A rapid alkaline extraction procedure for screening recombinant plasmid DNA. Nucleic Acids Res. 6:1513-1523.

4. Bolinches, J., A. E. Toranzo, A. Silva, and J. L. Barja. 1986. Vibriosis as the main causative factor of heavy mortalities in the oyster culture industry in northwestern Spain. Bull. Eur. Assoc. Fish Pathol. 6:1-4.

5. Bowser, P. R., R. Rosemark, and C. R. Reiner. 1981. A preliminary report of vibriosis in cultured American lobsters, Homarus americanus. J. Invertebr. Pathol. 37:80-85.

6. Chomezynski, P., and N. Sacchi. 1987. Single-step method of RNA isolation by acid guanidinium thiocyanate-phenol-chloroform extraction. Anal. Biochem. 162:156-159.

7. Colwell, R. R., and D. J. Grimes. 1984. Vibrio diseases of marine fish populations. Helgol. Meeresunters. 37:265-287.

8. De Borde, D. C., W. N. Clayton, M. L. Herlocher, and H. F. Maassab. 1986 Resolution of a common RNA sequencing ambiguity by terminal deoxynucleotidyl transferase. Anal. Biochem. 157:275-282.

9. De Soete, G. 1983. A least squares algorithm for fitting additive trees to proximity data. Psychometrika 48:621-626.

10. Dorsch, M., D. Lane, and E. Stackebrandt. 1992. Towards a phylogeny of the genus Vibrio based on 16S rRNA sequences. Int. J. Syst. Bacteriol. 42:58-63.

11. Dorsch, M., and E. Stackebrandt. Unpublished data.

12. Egidius, E. 1987. Vibriosis: pathogenicity and pathology. A review. Aquaculture 67:15-28.

13. Egidius, E., R. Wiik, K. Andersen, K. A. Hoff, and B. Hjeltnes. 1986. Vibrio salmonicida $\mathrm{sp.} \mathrm{nov.,} \mathrm{a} \mathrm{new} \mathrm{fish} \mathrm{pathogen.} \mathrm{Int.} \mathrm{J.} \mathrm{Syst.} \mathrm{Bacteriol.} \mathrm{36:518-520.}$

14. Embley, T. M., J. Smida, and E. Stackebrandt. 1988. Reverse transcriptase sequencing of $16 \mathrm{~S}$ ribosomal RNA from Faenia rectivirgula, Pseudonocardia thermophila and Saccharopolyspora hirsuta, three wall type IV actinomycetes which lack mycolic acids. J. Gen. Microbiol. 134:961-966.

15. Evelyn, T. P. T. 1971. First records of vibriosis in Pacific salmon cultured in Canada, and taxonomic status of the responsible bacterium. J. Fish. Res. Board Can. 28:517-525.

16. Fox, G. E., E. Stackebrandt, R. B. Hespell, J. Gibson, J. Maniloff, T. A. Dyer, R. S. Wolfe, W. E. Balch, R. S. Tanner, L. J. Magrum, L. B. Zablen, R Blakeore, R. Gupta, L. Bonen, B. J. Lewis, D. A. Stahl, K. R. Luehrsen, K. N. Chen, and C. R. Woese. 1980. The phylogeny of procaryotes. Science 209: 457-463.

17. Giorgetti, G., and G. Ceschia. 1982. Vibriosis in rainbow trout, Salmo gaird neri Richardson, in fresh water in north-eastern Italy. J. Fish Dis. 5:125-130.

18. Grisez, L., R. Ceusters, and F. Ollevier. 1991. The use of API 20E for the identification of Vibrio anguillarum and V. ordalii. J. Fish Dis. 14:359-365.

19. Harrell, L. W., A. J. Novotny, M. H. Schiewe, and H. O. Hodgins. 1976 Isolation and description of two vibrios pathogenic to Pacific salmon in Puget Sound, Washington. Fish. Bull. (Dublin) 74:447-449.

20. Jeffries, V. E. 1982. Three Vibrio strains pathogenic to larvae of Crassostrea gigas and Ostrea edulis. Aquaculture 29:201-226.

21. Jukes, T. H., and C. R. Cantor. 1969. Evolution of protein molecules, p. 21-132. In H. N. Munro (ed.), Mammalian protein metabolism. Academic Press, New York.

22. Kita-Tsukamoto, K., H. Oyaizu, K. Nanba, and U. Simidu. 1993. Phylogenetic relationships of marine bacteria, mainly members of the family Vibrionaceae, determined on the basis of $16 \mathrm{~S}$ rRNA sequences. Int. J. Syst. Bacteriol. 43:8-19.

23. Knappskog, D. H., O. M. Rødseth, E. Slinde, and C. Endresen. 1993. Immunochemical analysis of Vibrio anguillarum strains isolated from cod, $\mathrm{Ga}$ dus morhua L., suffering from vibriosis. J. Fish Dis. 16:327-338.

24. Lane, D. J., B. Pace, G. J. Olson, D. A. Stahl, M. L. Sogin, and R. Pace. 1985. Rapid determination of 16S ribosomal RNA sequences for phylogenetic analyses. Proc. Natl. Acad. Sci. USA 82:6955-6959.

25. Larsen, J. L., K. Pedersen, and I. Dalsgaard. 1994. Vibrio anguillarum serovars associated with vibriosis in fish. J. Fish Dis. 17:259-267.

26. Love, M., D. Teebken-Fisher, J. E. Hose, J. J. Farmer III, F. W. Hickman, and G. R. Fanning. 1981. Vibrio damsela, a marine bacterium, causes skin ulcers on the damselfish Chromis punctipinnis. Science 214:1139-1140.

27. MacDonell, M. T., and R. R. Colwell. 1985. Phylogeny of the Vibrionaceae, and recommendation for two new genera, Listonella and Shewanella. Syst Appl. Microbiol. 6:171-182.

28. Martinez-Picado, J., A. B. Blanch, and J. Jofre. 1994. Rapid detection and identification of Vibrio anguillarum by using a specific oligonucleotide probe complementary to 16S rRNA. Appl. Environ. Microbiol. 60:732-737.

29. Oeding, P. 1957. Agglutinability of pyrogenic staphylococci at various conditions. Acta Pathol. Microbiol. Scand. 41:310-324.

30. Ohnishi, K., and K. Muroga. 1976. Vibrio sp. as a cause of disease in rainbow trout cultured in Japan. I. Biochemical characteristics. Fish Pathol. 11:159-165. 
31. Ohnishi, K., and K. Muroga. 1977. Vibrio sp. as a cause of disease in rainbow trout cultured in Japan. II. Physiological characteristics and pathogenicity. Fish Pathol. 12:51-55.

32. Olsen, G. J. R. Overbeek, N. Larsen, T. L. Marsh, M. J. McCaughey, M. A MacTukenas, W.-M. Kuan, T. J. Macke, Y. Xing, and C. R. Woese. 1992. The Ribosomal Database Project. Nucleic Acids Res. 20:2199-2200.

33. Onarheim, A. M., R. Wiik, J. Burghardt, and E. Stackebrandt. 1994. Characterization and identification of two Vibrio species indigenous to the intestine of fish in cold sea water; description of Vibrio iliopiscarius sp. nov. Syst. Appl. Microbiol. 17:370-379.

34. Powell, J. L., and M. W. Loutit. 1990. Isolation and characterisation of Vibrio anguillarum from selected marine sites in New Zealand. N. Z. J. Mar. Freshwater Res. 24:267-273.

35. Rehnstam, A.-S., A. Norquist, H. Wolf-Watz, and Å. Hagstrøm. 1989. Identification of Vibrio anguillarum in fish by using partial 16S rRNA sequences and a specific 16S rRNA oligonucleotide probe. Appl. Environ. Microbiol. 55:1907-1910.

36. Renault, T., P. Haffiner, C. Mal-Fondet, and M. Weppe. 1994. Vibrio damsela as a pathogenic agent causing mortalities in cultured sea bass (Lates calcarifer). Bull. Eur. Assoc. Fish Pathol. 14:117-118.

37. Rødseth, O. M., and K. Andersen. Unpublished data.

38. Rødseth, O. M., D. H. Knappskog, K. Andersen, and C. Endresen. Submitted for publication.

39. Ruimy, R., V. Breittmayer, P. Elbaze, B. Lafay, O. Boussemart, M. Gauthier, and R. Christen. 1994. Phylogenetic analysis and assessment of the genera Vibrio, Photobacterium, Aeromonas, and Plesiomonas deduced from smallsubunit rRNA sequences. Int. J. Syst. Bacteriol. 44:416-426.

40. Schiewe, M. H., and J. H. Crosa. 1981. Molecular characterization of Vibrio anguillarum biotype 2. Can. J. Microbiol. 27:1011-1018

41. Schiewe, M. H., T. J. Trust, and J. H. Crosa. 1981. Vibrio ordalii sp. nov.: a causative agent of vibriosis in fish. Curr. Microbiol. 6:343-348.

42. Schleifer, K. H., and W. Ludwig. 1989. Phylogenetic relationship among bacteria, p. 103-117. In B. Fernholm, K. Bremer, and H. Jornwall (ed.), The hierarchy of life. Elsevier Science Publishers, Amsterdam.

43. Sørensen, U. B. S., and J. L. Larsen. 1986. Serotyping of Vibrio anguillarum.
Appl. Environ. Microbiol. 51:593-597.

44. Sørum, H., A. B. Hvaal, M. Heum, F. L. Daae, and R. Wiik. 1990. Plasmid profiling of Vibrio salmonicida for epidemiological studies of cold-water vibriosis in Atlantic salmon (Salmo salar) and cod (Gadus morhua). Appl. Environ. Microbiol. 56:1033-1037.

45. Stackebrandt, E. 1988. Phylogenetic relationships vs. phenotypic diversity: how to achieve a phylogenetic classification system of the eubacteria. Can. J. Microbiol. 34:552-556

46. Stackebrandt, E., W. Liesack, and D. Witt. 1992. Ribosomal RNA and rDNA sequence analyses. Gene 115:255-260.

47. Tolmasky, M. E., L. A. Actis, A. E. Toranzo, J. L. Barja, and J. H. Crosa 1985. Plasmids mediating'iron uptake in Vibrio anguillarum strains isolated from turbot in Spain. J. Gen. Microbiol. 131:1989-1997.

48. Toranzo, A. E., and J. L. Barja. 1990. A review of the taxonomy and seroepizootiology of Vibrio anguillarum, with special reference to aquaculture in the northwest of Spain. Dis. Aquat. Org. 9:73-82.

49. Toranzo, A. E., J. L. Barja, S. A. Potter, R. R. Colwell, F. M. Hetrick, and J. H. Crosa. 1983. Molecular factors associated with virulence of marine vibrios isolated from striped bass in Chesapeake Bay. Infect. Immun. 39: 1220-1227.

50. Valle, O., M. Dorsch, R. Wiik, and E. Stackebrandt. 1990. Nucleotide sequence of the 16S rRNA from Vibrio anguillarum. Syst. Appl. Microbiol. 13:257

51. Wiik, R., K. Andersen, F. L. Daae, and K. A. Hoff. 1989. Virulence studies based on plasmid profiles of the fish pathogen Vibrio salmonicida. Appl Environ. Microbiol. 55:819-825.

52. Wiik, R., and E. Egidius. 1986. Genetic relationships of Vibrio salmonicida sp. nov. to other fish-pathogenic vibrios. Int. J. Syst. Bacteriol. 36:521-523.

53. Wiik, R., K. A. Hoff, K. Andersen, and F. L. Daae. 1989. Relationships between plasmids and phenotypes of presumptive strains of Vibrio anguillanum isolated from different fish species. Appl. Environ. Microbiol. 55:826831.

54. Woese, C. R. 1987. Bacterial evolution. Microbiol. Rev. 51:221-271.

55. Woese, C. R., E. Stackebrandt, T. Macke, and G. E. Fox. 1985. A definition of the eubacterial "divisions." Syst. Appl. Microbiol. 6:143-151. 